\title{
RAPID DEPLOYMENT AND SUTURELESS AORTIC PROSTHESES. Time to validate unusual or 'off label' indications?
}

\author{
Igor Vendramin ${ }^{1}$, Uberto Bortolotti ${ }^{1}$, and Ugolino Livi ${ }^{1}$ \\ ${ }^{1}$ University Hospital of Udine
}

September 10, 2020

\begin{abstract}
Currently available evidence supports the safety and efficacy of rapid deployment and sutureless prostheses for aortic valve replacement (AVR) in aortic stenosis as suggested by the International Expert Consensus in 2016. Following the increasing experience and the good results obtained in AVR, the use of sutureless and rapid deployment prostheses in peculiar situations, at times as an 'off-label' indication, has been reported demonstrating to represent an effective solution to challenging surgical problems, such as described by Piperata et al. in a recent issue of the Journal of Cardiac Surgery for the treatment of active infective endocarditis complicated by an extensive aortic annulus abscess. The considerable experience acquired so far with rapid deployment and sutureless valves has stimulated many surgeons to use such devices in patients in whom limiting the overall ischemic time is felt to be of paramount importance, but also in different surgical scenarios. Therefore, we believe the time has come to strongly support the unusual or even 'off label' employment of these devices by including them in future recommendations.
\end{abstract}

\section{RAPID DEPLOYMENT AND SUTURELESS AORTIC PROSTHESES}

Time to validate unusual or 'off label' indications?

Igor Vendramin, $\mathrm{MD}^{1}$, Uberto Bortolotti, $\mathrm{MD}^{1}$, Ugolino Livi, $\mathrm{MD}^{1,2}$

${ }^{1}$ Cardiothoracic Department, University Hospital, Udine, Italy

${ }^{2}$ Department of Medical Area (DAME), University of Udine

Address correspondence to: I. Vendramin, MD, Cardiothoracic Department,

P. le S.M. Misericordia 15, Udine, Italy

Tel: 39-432-552431; Fax: 39-432-552975

e-mail:vendramin.igor@gmail.com

Word count: 498

Currently available evidence supports the safety and efficacy of rapid deployment and sutureless prostheses for aortic valve replacement (AVR) in aortic stenosis as suggested by the International Expert Consensus in 2016 (1). Furthermore, a systematic review and meta-analysis of recipients of Perceval sutureless (LivaNova Group, Saluggia, Italy ), 3F Enable (Medtronic, Inc, Minneapolis, MN, USA ) or Intuity Elite valves (Edwards Lifesciences, Irvine, CA, USA ) has confirmed that employment of all such devices, even using a miniinvasive approach, is associated with shorter cross-clamp and cardiopulmonary bypass times when compared to conventional implant of standard bioprostheses (1). 
Following the increasing experience and the good results obtained in AVR, recent reports indicate suitability of sutureless and rapid deployment prostheses to be used in different scenarios and peculiar surgical situations. In a recent issue of the Journal of Cardiac Surgery, Piperata et al. have described a patient with active infective endocarditis, complicated by an extensive aortic annulus abscess, who was successfully treated with aortic root reconstruction using a double pericardial patch followed by AVR with a rapid deployment prosthesis (2). At 6-month follow-up the echocardiographic control has shown a normal prosthetic function without evidence of perivalvular leaks.

The use of sutureless prostheses in peculiar situations, at times as an 'off-label' indication, has been reported previously demonstrating to represent an effective solution to challenging surgical problems. A Perceval prosthesis has been employed for AVR in failing homografts and stentless aortic roots when standard reoperations appeared extremely hazardous or cumbersome (3). In 2019, Martinelli and colleagues reported a patient with severe aortic regurgitation and a porcelain aorta in whom limited AVR was performed implanting a Perceval bioprosthesis (4). After 2 years the patient is in NYHA class I and with no paravalvular leaks at transthoracic echo.

We have recently described a patient in whom a Perceval bioprosthesis was implanted after intraoperative failure of a valve-sparing procedure, since any attempt to a further repair was considered time consuming and with limited chances of success. Three years postoperatively, the patient is asymptomatic with a normally functioning aortic prosthesis (5).

The considerable experience acquired so far with rapid deployment and sutureless valves has stimulated many surgeons to use such devices not only for standard AVR, particularly in patients in whom limiting the overall ischemic time is felt to be of paramount importance, but also in different surgical scenarios. In this respect the interesting paper by Piperata et al. shows another possible indication aimed to facilitate complex index or redo procedures (2). Therefore, we believe the time has come to strongly support the unusual or even 'off label' employment of these devices by including them in future recommendations.

\section{REFERENCES}

1. Glauber M, Moten SC, Quaini E, et al. International expert consensus on sutureless and rapid deployment valves in aortic valve replacement using minimally invasive approaches. Innovations 2016; 11:165-173.

2. Piperata A, Bottio T, Avesani MD, Folino G, Bellanti E, Gerosa G. Use of rapid- deployment aortic valve prosthesis and patch reconstruction in complex endocarditis. J Card Surg 2020; 35:2056-2058.

3. Chiariello GA, Villa E, Messina A, et al. Perceval valve-in-valve implant for full root xenograft failure. J Card Surg. 2017;1-4.

4. Martinelli GL, Cotroneo A, Stelian E, Benea D, Diena M. A new approach for severe aortic regurgitation in porcelain aorta with sutureless Perceval valve: A case report. Intern J Surg Case Rep 2019; 59: 124-127.

5. Vendramin I, Piani D, Sponga S, Bortolotti U, Livi U. Immediate failure of a valve- sparing procedure: repair with a Perceval sutureless prosthesis. J Cardiovasc Med 2020. 